\title{
Controversies in pulmonary hypertension due to left heart disease
} Martino Cheli ${ }^{1}$ and Jean Luc Vachiery ${ }^{2 *}$

\author{
Addresses: ${ }^{1}$ Department of Internal Medicine, University of Genoa, Via Balbi, 5, 16126 Genova, Italy; ${ }^{2}$ Department of Cardiology, Hôpital Erasme, \\ Université Libre de Bruxelles, Franklin Rooseveltlaan 50, 1050 Brussel, Belgium \\ *Corresponding author: Jean Luc Vachiery (jeanluc.vachiery@erasme.ulb.ac.be) \\ Fl000Prime Reports 2015, 7:07 (doi:10.12703/P7-07) \\ All FI000Prime Reports articles are distributed under the terms of the Creative Commons Attribution-Non Commercial License \\ (http://creativecommons.org/licenses/by-nc/3.0/legalcode), which permits non-commercial use, distribution, and reproduction in any medium, \\ provided the original work is properly cited. \\ The electronic version of this article is the complete one and can be found at: http://fl $000 . c o m / p r i m e / r e p o r t s / m / 7 / 7$
}

\begin{abstract}
Left heart failure is currently the most prevalent cause of pulmonary hypertension $(\mathrm{PH})$ worldwide and this is due mainly to the increased left ventricular and pulmonary venous pressures seen in this condition. Still, a quota of patients with left heart failure will have a pulmonary arterial disease "disproportionate" to the initial increase of left-sided pressures. Whatever the mechanism involved, the appearance of $\mathrm{PH}$ is a powerful marker, as it determines decreased exercise tolerance and survival. To date, all trials using therapies approved for pulmonary arterial hypertension (PAH) failed to demonstrate a benefit in the context of heart failure (HF) without or with $\mathrm{PH}$. In addition, the comparison among studies is limited by relevant differences in definitions, methodology, and timing of assessment. A novel rigorous hemodynamic classification based on the diastolic pulmonary gradient has been recently proposed to better characterize this form of $\mathrm{PH}$. This will promote uniformity in patient populations and end-points for future clinical trials.
\end{abstract}

\section{Introduction}

An abnormal increase of pressures in the pulmonary vascular bed, or $\mathrm{PH}$, can be a relatively common consequence of several cardiac, pulmonary, and systemic disorders [1] but also of the aging process. Left heart diseases (LHDs), mainly HF with preserved or reduced ejection fraction (HFpEF or HFrEF) and valvular heart disease, represent the most frequent causes of $\mathrm{PH}$ (PH-LHD) through the increase of left ventricular filling pressures and pulmonary venous pressures [2]. Presence of PH-LHD is associated with a decrease in exercise tolerance, worsening of dyspnea, and reduced survival [2-5].

Several drug regimens approved for PAH (a rare disease) have been tested in clinical trials to treat heart failure, with or without PH-LHD: all have yielded disappointing results so far. This emphasizes the specificities of PH-LHD, the importance of an appropriate hemodynamic classification, and the need for a strict selection of patients and endpoints for clinical trials. In this brief review, we will provide insights into the main areas of controversy in PH-LHD.

\section{How is pulmonary hypertension due to left heart disease defined and diagnosed?}

PH-LHD is diagnosed by right or left heart catheterization (or both) when the mean pulmonary pressure (PAPm) is superior to $25 \mathrm{~mm} \mathrm{Hg}$ and the pulmonary capillary wedge pressure (PAWP) or the left ventricular end-diastolic pressure exceeds $15 \mathrm{~mm} \mathrm{Hg}$. PAWP is definitely a surrogate measure for left ventricular enddiastolic pressure that is increased by a variety of cardiac diseases. The mechanism of PH-LHD is represented in Figure 1 . In the resting pulmonary circulation, in which approximately 1:1 backward transmission of pressure can be observed between the left atrium and the diastolic pulmonary pressure (PAPd), every $1 \mathrm{~mm} \mathrm{Hg}$ increase of left atrial pressure corresponds to a $1 \mathrm{~mm} \mathrm{Hg}$ increase in PAPd. This relatively simple equation displays how HFpEF, HFrEF, and valvular heart disease may generate $\mathrm{PH}$. However, the increase in left atrial pressures has a much more prominent impact on the elevation of systolic pulmonary arterial pressure and mean pulmonary pressures than of PAPd and further depends on cardiac output $[2,6]$. In rare cases, patients will develop a 


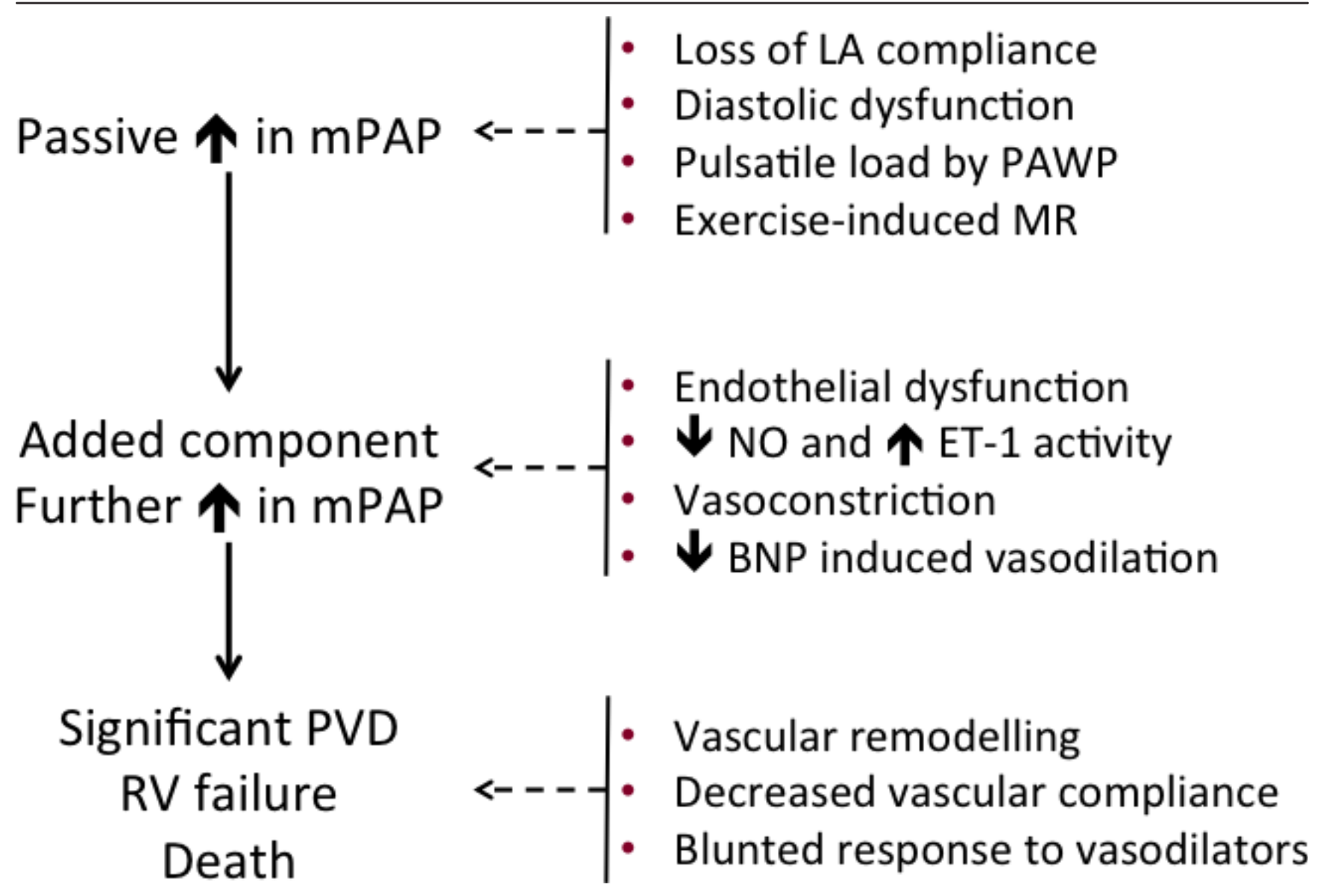

Abbreviations: BNP, brain natriuretic peptide; ET-I, endothelin-I; LA, left atrium; mPAP, mean pulmonary arterial pressure; MR, mitral regurgitation; PAWP, pulmonary capillary wedge pressure; PVD, pulmonary vascular disease; RV, right ventricle. Reproduced with permission of the editor from Vachiery and colleagues [2].

significant pre-capillary pulmonary vascular disease that is not entirely explained by a passive increase in left atrial pressure. To date, the pre-capillary, or arterial, component of PH-LHD has been defined on the basis of transpulmonary gradient (TPG) (that is, TPG $=$ PAPm PAWP; normal TPG $\leq 12 \mathrm{~mm} \mathrm{Hg}$ ) with a wide variety of definitions and terminologies (among others, "reactive", "out of proportion", and "mixed" PH) [2]. Confusion has been further promoted by the inappropriate extension of vasodilator testing to this subgroup of patients, with consequent spreading of an anomalous overlap between PAH and PH-LHD and some expectation for a treatable component of the disease.

In the attempt to harmonize definitions, an updated hemodynamic classification based on the diastolic pulmonary difference (DPD) has been recently proposed for PH-LHD [2]. The DPD has several advantages: it is virtually absent in healthy individuals, is less dependent than the transpulmonary gradient $(\mathrm{TPG}=\mathrm{PAPm}-\mathrm{PAWP}$; normal TPG $\leq 12 \mathrm{~mm} \mathrm{Hg}$ ) from stroke volume and PAWP, and has been shown to provide added prognostic value to the TPG [7]. This classification labels patients with high PAWP (>15 mm Hg) and low DPD $\left(<7 \mathrm{~mm} \mathrm{Hg}\right.$ ) as having "isolated post-capillary $\mathrm{PH}^{\prime}$ and patients with high PAWP and DPD $(>7 \mathrm{~mm} \mathrm{Hg}$ ) as having "combined post-capillary $\mathrm{PH}$ and pre-capillary $\mathrm{PH}^{\prime \prime}(\mathrm{CpcPH})$. Essentially, this describes the hemodynamic status while avoiding any forecast on the components of vasoconstriction and remodeling.

\section{How frequent is it?}

As previously mentioned, the lack of a uniform definition limits the comparison among available studies as well as the precise estimation of incidence and prevalence of PH-LHD. The existing variations in the epidemiology of PH-LHD depend largely on differences in methodology of evaluation (prospective versus retrospective), disease 
classification, patient selection criteria (age, risk factors, and left ventricular systolic function), technique of pulmonary pressure assessment (hemodynamic versus non-invasive), and previous fluid optimization. As an example, the prevalence of moderate to severe $\mathrm{PH}$ at echocardiography among 11,327 suspected HF patients retrospectively included in the Euro Heart Survey was 16\% [8] but rose to $62 \%$ at invasive evaluation in a smaller prospective study performed by Ghio and colleagues [9] in 379 consecutive patients with an ejection fraction of less than $35 \%$.

More recently, Damy and colleagues [5], using an echocardiographic cut-off value of $35 \mathrm{~mm} \mathrm{Hg}$ for the tricuspid gradient, showed respective proportions of $\mathrm{PH}$ in $30 \%, 18 \%$, and $4 \%$ of HFrEF, HFpEF, and no-HF patients, respectively; of note, the prevalences fell to $6 \%$, $7 \%$, and $8 \%$ when those without a measurable tricuspid regurgitation jet were included. Applying the same echocardiographic limit to a population of 244 consecutive patients with HFpEF, another study yielded a remarkable $83 \%$ prevalence of $\mathrm{PH}$ [10]. These wide differences highlight well how definitions and diagnostic protocols may affect results and the importance of invasive evaluation as gold standard for quantifying pressures, cardiac output, and pulmonary vascular resistances (PVRs) in $\mathrm{PH}$. Recent data suggest that the prevalence of $\mathrm{CpcPH}$ is around $12 \%$ in patients with HF [7].

\section{How important is pulmonary hypertension due to left heart disease?}

Clear evidence that PH increases mortality in HF independently from the underlying cause emerged from the first reports more than 20 years ago [11,12]. The available data confirm that prognosis of HFpEF is comparable to or only faintly better than that of HFrEF; moreover, in both conditions, the decrease in survival is similarly proportional to the elevation of pulmonary systolic pressure even if the majority of patients will present with only a mild to moderate degree of $\mathrm{PH}$. Accuracy of risk estimation can be further increased on the basis of the PH subtype: mixed PH (or combined preand post-capillary PH, PVR of at least 3 Wood units) has a largely higher risk of death than passive PH (or isolated post-capillary PH, PVR of less than 3 Wood units hazard ratio 1.55) [13]. In the previously mentioned study from Ghio and colleagues [9], right ventricular function, New York Heart Association functional class, left ventricular end-diastolic diameter index, and PAPm were all independent survival predictors at multivariate analysis; interestingly, despite confirmation that PAPm and right ventricular ejection fraction are inversely related, the latter kept its prognostic value only in the subgroup of patients with high PAPm. This confirms the importance of the right ventricular response to afterload over the absolute value of pressures as a determinant for survival in PH-LHD.

At present, fewer data are available on the prognostic impact of other parameters employed for diagnosis, such as DPD and TPG [14]. In a recent work, DPD increased prediction of survival in 1094 patients undergoing invasive evaluation for confirmation of $\mathrm{PH}$ : at a median follow-up of 78 months, combined pre- and postcapillary $\mathrm{PH}$ had the same worse outcomes as precapillary PH [7]. However, this was not confirmed by a subsequent retrospective analysis of the hemodynamic data of 5827 orthotopic heart transplant recipients with pre-transplant PH and elevated TPG and PVR: the posttransplant survival rate at five years was similar when a stratification on the basis of DPG was performed [15]. One of the limitations of the latter lies in the selected population studied; that is, only the patients undergoing transplant were studied, and naturally patients with significant pulmonary vascular disease were excluded.

\section{Should pulmonary hypertension due to left heart disease be treated?}

Besides the controversies in definition and diagnosis of PH-LHD, the general agreement is that treatment of PH-LHD should start with aggressive management of the underlying cardiac disease and of any other potential confounding factor, such as respiratory tract infections, sleep apnea syndrome, arrhythmias, or pulmonary embolism. Aggressive control of cardiovascular risk factors is also recommended.

There is no specific treatment for PH-LHD, though. Diuretics are the mainstay of medical treatment for fluid control and relief of congestion, whereas angiotensinconverting enzyme inhibitors and $\beta$-blockers are indicated to improve morbidity and long-term survival in HF. Some subsets of patients may benefit from invasive monitoring and cyclic inotropic support to optimize volume status, alleviate symptoms, or reduce hospitalizations (or a combination of these), although the long-term benefit of this strategy remains uncertain. When appropriate, corrective/palliative surgery for valvular heart disease should be considered, along with the implantation of cardiac resynchronization therapy or implantable cardiac defibrillators for those with QRS of more than 120 ms and ejection fraction of less than 35\%. If clinically indicated, younger patients unresponsive to medical treatment should be evaluated for heart transplantation or implantation of ventricular assist devices to support cardiac output, either as a bridge to transplant or as destination therapy. For this indication, the pre-transplant assessment of reversibility of PH-LHD is particularly relevant. 
The appealing hypothesis of targeting PH-LHD with drugs approved for PAH has been supported by affinities in the increase of endothelin-1 levels and in the impairment of nitric oxide-mediated vasodilation; small single-center therapeutic trials have reported improvement of exercise capacity and hemodynamic parameters [16-18]. However, the results of randomized trials have been largely unsatisfactory, if not detrimental, with most of the compounds. In our opinion, this has several reasons. First, patients were generally not stratified on the basis of $\mathrm{PH}$, nor was hemodynamic evaluation systematically performed. Second, with the exception of phosphodiesterase-5 inhibitors, mostly patients with HFrEF were enrolled and patients with valvular heart disease were excluded. Third, preliminary optimization of volume status was not required for inclusion. Lastly, high dosages of compounds were used in order to attain systemic effects.

As a result, data coming from multicenter randomized trials are scarce. In fact, only two of these trials are available in the literature. In a multicentric placebocontrolled trial [19], riociguat (a soluble guanylate cyclase stimulator approved for $\mathrm{PAH}$ and chronic thromboembolic pulmonary hypertension) was compared with placebo in 201 patients with PH due to HF-rEF during 16 weeks. No effect on the primary endpoint (a change in PAPm after 16 weeks) was observed at any dose of riociguat compared with placebo. A proof-of-concept study to test the acute effects of riociguat in patients with $\mathrm{PH}$ associated with diastolic dysfunction (NCT01172756) has recently been published, with similar negative results [20].

Two multicenter clinical trials in PH-LHD are currently under way with the phosphodiesterase 5 inhibitors sildenafil (NCT01616381) and tadalafil (NCT01910389). Although these trials plan to include a well-defined population with $\mathrm{PH}$ due to systolic HF, the absence of right heart catheterization validation of $\mathrm{PH}$ might represent a significant limitation.

Finally, a pilot phase II study with the endothelin receptor antagonist macitentan (MELODY-1) (NCT02070991) is the only trial including patients falling in the new definition of $\mathrm{CpcPH}$. Until results from large trials are available, PH-LHD should not be treated with drugs approved to treat $\mathrm{PAH}$.

\section{Conclusions}

Despite several advances in assessment and classification, PH-LHD is still an under-recognized threatening complication of LHDs. A new definition and harmonized terminology will provide a better identification of a subset of patients who deserve special attention. In this area of unmet clinical need, proof-of-concept studies are needed to implement larger randomized trials, along with robust clinical end-points. Combined pre- and postcapillary PH appears to be one of the main fields of interest for therapeutic trials with PAH-specific drugs. This should lead to better use of resources, at least by decreasing inappropriate off-label drug use in this context.

\section{Abbreviations}

$\mathrm{CpcPH}$, combined post-capillary pulmonary hypertension and pre-capillary pulmonary hypertension; DPD, diastolic pulmonary difference; HF, heart failure; HFpEF, heart failure with preserved ejection fraction; HFrEF, heart failure with reduced ejection fraction; LHD, left heart disease; PAH, pulmonary arterial hypertension; PAPd, diastolic pulmonary arterial pressure; PAPm, mean pulmonary pressure; PAWP, pulmonary capillary wedge pressure; $\mathrm{PH}$, pulmonary hypertension; $\mathrm{PH}-\mathrm{LHD}$, pulmonary hypertension left heart disease; PVR, pulmonary vascular resistances; TPG, transpulmonary gradient.

\section{Disclosures}

Jean Luc Vachiery has received consultancy and speaker fees from Actelion Pharmaceuticals and Bayer Schering. Martino Cheli declares that he has no disclosures.

\section{References}

I. Simonneau G, Gatzoulis MA, Adatia I, Celermajer D, Denton C, Ghofrani A, Gomez Sanchez MA, Krishna Kumar R, Landzberg M, Machado RF, Olschewski H, Robbins IM, Souza R: Updated clinical classification of pulmonary hypertension. J Am Coll Cardiol 20I3, 62(25 Suppl):D34-4I.

\section{FlOOOPrime}

\section{RECOMMENDED}

2. Vachiéry J-L, Adir Y, Barberà JA, Champion H, Coghlan JG, Cottin V, De Marco T, Galiè N, Ghio S, Gibbs JS, Martinez F, Semigran M, Simonneau G, Wells A, Seeger W: Pulmonary hypertension due to left heart diseases. J Am Coll Cardiol 2013, 62(25 Suppl):DI00-8.

3. Bursi F, McNallan S, Redfield MM, Nkomo VT, Lam CS, Weston SA, Jiang R, Roger VL: Pulmonary Pressures and Death in Heart Failure: A Community Study. J Am Coll Cardiol 2012, 59:222-31.

\section{FlOOOPrime}

\section{RECOMMENDED}

4. Owan TE, Hodge DO, Herges RM, Jacobsen SJ, Roger VL, Redfield MM: Trends in prevalence and outcome of heart failure with preserved ejection fraction. N Engl J Med 2006, 355:25 I-9.

\section{FlOOOPrime}

\section{RECOMMENDED}

5. Damy T, Goode KM, Kallvikbacka-Bennett A, Lewinter C, Hobkirk J, Nikitin NP, Dubois-Randé JL, Hittinger L, Clark AL, Cleland JG: Determinants and prognostic value of pulmonary arterial pressure in patients with chronic heart failure. Eur Heart J 2010, 3 I:2280-90.

\section{FlOOOPrime}

RECOMMENDED 
6. Naeije R, Vachiery J-L, Yerly P, Vanderpool R: The transpulmonary pressure gradient for the diagnosis of pulmonary vascular disease. Eur Respir J 2013, 41:217-23.

\section{FlOOOPrime}

\section{RECOMMENDED}

7. Gerges C, Gerges M, Lang MB, Zhang Y, Jakowitsch J, Probst P, Maurer G, Lang IM: Diastolic pulmonary vascular pressure gradient: a predictor of prognosis in "out-of-proportion" pulmonary hypertension. Chest 2013, 143:758-66.

\section{FlOOOPrime
RECOMMENDED}

8. Cleland JGF, Swedberg K, Follath F, Komajda M, Cohen-Solal A, Aguilar JC, Dietz R, Gavazzi A, Hobbs R, Korewicki J, Madeira HC, Moiseyev VS, Preda I, van Gilst WH, Widimsky J, Freemantle N, Eastaugh J, Mason J: The EuroHeart Failure survey programme- a survey on the quality of care among patients with heart failure in Europe. Part I: patient characteristics and diagnosis. Eur Heart J 2003, 24:442-63.

\section{FlOOOPrime}

\section{RECOMMENDED}

9. Ghio S, Gavazzi A, Campana C, Inserra C, Klersy C, Sebastiani R, Arbustini E, Recusani F, Tavazzi L: Independent and additive prognostic value of right ventricular systolic function and pulmonary artery pressure in patients with chronic heart failure. J Am Coll Cardiol 200 I, 37:183-8

\section{FlOOOPrime}

RECOMMENDED

10. Lam CSP, Roger VL, Rodeheffer RJ, Borlaug BA, Enders FT, Redfield MM: Pulmonary Hypertension in Heart Failure with Preserved Ejection Fraction: A Community-Based Study. JACC 2009, 53: I I 19-26.

\section{FlOOPrime}

\section{RECOMMENDED}

II. Abramson SV, Burke JF, Kelly JJ, Kitchen JG 3rd, Dougherty MJ, Yih DF, McGeehin FC 3rd, Shuck JW, Phiambolis TP: Pulmonary hypertension predicts mortality and morbidity in patients with dilated cardiomyopathy. Ann Intern Med 1992, I I 6:888-95.

\section{FIOOOPrime}

12. Costard-Jackle A, Fowler MD: Influence of Preoperative Pulmonary Artery Pressure on Mortality After Heart Transplantation: Testing of Potential Reversibility of Pulmonary Hypertension With Nitroprusside Is Useful in Defining a High Risk Group. J Am Coll Cardiol 1992, 19:48-54.

\section{FlOOOPrime}

\section{RECOMMENDED}

13. Miller WL, Grill DE, Borlaug B: Clinical features, hemodynamics, and outcomes of pulmonary hypertension due to chronic heart failure with reduced ejection fraction: pulmonary hypertension and heart failure. JACC Heart Fail 2013, I:290-9.

\section{FlOOOPrime}

14. Aronson D, Eitan A, Dragu R, Burger AJ: Relationship between reactive pulmonary hypertension and mortality in patients with acute decompensated heart failure. Circ Heart Fail $201 \mathrm{I}$, 4:644-50.

\section{FlOOOPrime}

\section{RECOMMENDED}

15. Tedford RJ, Beaty CA, Mathai SC, Kolb TM, Damico R, Hassoun PM, Leary PJ, Kass DA, Shah AS: Prognostic value of the pretransplant diastolic pulmonary artery pressure-to-pulmonary capillary wedge pressure gradient in cardiac transplant recipients with pulmonary hypertension. J Heart Lung Transplant 2014, 33:289-97.

FlOOOPrime

16. Lewis GD, Lachmann J, Camuso J, Lepore J, Shin J, Martinovic ME, Semigran MJ: Sildenafil improves exercise hemodynamics and oxygen uptake in patients with systolic heart failure. Circulation 2007, I I5:59-66.

17. Lewis GD, Shah R, Shahzad K, Camuso JM, Pappagianopoulos PP, Hung J, Semigran MJ: Sildenafil improves exercise capacity and quality of life in patients with systolic heart failure and secondary pulmonary hypertension. Circulation 2007, | | 6:1555-62.

18. Guazzi M, Samaja M, Arena R, Vicenzi M, Guazzi MD: Long- term use of sildenafil in the therapeutic management of heart failure. J Am Coll Cardiol 2007, 50:2136-44.

19. Bonderman D, Ghio S, Felix SB, Ghofrani HA, Michelakis E, Mitrovic V, Oudiz RJ, Boateng F, Scalise AV, Roessig L, Semigran MJ: Left Ventricular Systolic Dysfunction Associated With Pulmonary Hypertension Riociguat Trial (LEPHT) Study Group: Riociguat for patients with pulmonary hypertension caused by systolic left ventricular dysfunction: a phase Ilb double-blind, randomized, placebo-controlled, dose-ranging hemodynamic study. Circulation 2013, I28:502-II.

\section{FlOOOPrime}

\section{RECOMMENDED}

20. Bonderman D, Pretsch I, Steringer-Mascherbauer $R$, Jansa $P$, Rosenkranz S, Tufaro C, Bojic A, Lam CS, Frey R, Ochan Kilama M, Unger S, Roessig L, Lang IM: Acute Hemodynamic Effects of Riociguat in Patients with Pulmonary Hypertension Associated with Diastolic Heart Failure (DILATE-I): A Randomized, Double-Blind, Placebo-Controlled, Single-Dose Study. Chest 20|4, |46:|274-85. 